\title{
Localization of Amylase Activity in the Digestive Organs of the Mozambique Mouthbrooder, Tilapia mossambica, and Bluegill, Lepomis macrochirus, Determined by A Starch Substrate Film Method.*
}

\author{
Shinichi Yamane \\ (Received December 2, 1972)
}

\begin{abstract}
The purpose of this study is to detect the localization of amylase activity of fish which are possessed of the stomach or both the stomach and the pyloric caeca by a starch substrate film method, and to make clear the question whether other organs than the pancreas are concerned with the secretion of amylase. In Mozambique mouthbrooder amylolytic activity was found in the pancreatic exocrine tissues, at the luminal surfaces and the lumen of the intestine, and at the outer- and outside of the tracts of the stomach and the intestine. In bluegill the activity was found also in the pancreatic exocrine tissues; at the luminal surfaces and the lumen of the esophagus, the stomach, the pyloric caeca and the intestine; and at the outer- and outside of the wall of the pyloric caeca and the intestine. In both the examined species the mucosa and submucosa showed to be amylase-negative throughout the digestive tract. In sections of the pyloric caeca of bluegill and of the intestine of both species, stained with hematoxylin and eosin, pancreatic ramifications were found to be embedded in or adhere to the wall of the tracts. From the present evidences it seems that amylase production is confined to the pancreatic exocrine cells alone and the mucosal epithelial cells of the digestive tract are not associated with production or secretion of amylase. The present results are accordant with those obtained for the carp, a stomachless fish, which was earlier examined.
\end{abstract}

There has been a controversy about locality of amlyase production of teleosts. A few investigators ${ }^{1,2)}$ were confident of amylase production to be confined to the pancreas alone. Many investigators ${ }^{3-12}$, however, considered that amylase might be secreted not only from the pancreas but also from the mucosal cells of the digestive tract.

The localization of amylase of the carp, a stomachless fish, were studied previous ${ }^{13}$. The purpose of this study is to detect the localization of amylase of fishes which possess the stomach or both the stomach and the pyloric caeca by a starch substrate film method, and solve a question whether any organ other than the pancreas is concerned with production or secretion of amylase.

\section{Materials and Methods}

A Mozambique mouthbrooder, $14.7 \mathrm{~cm}$ in standard length and two individuals of bluegill, 13.5 and $8.0 \mathrm{~cm}$, respectively, were used in this study. The former was fed

* A part of this investigation was supported by a Grant-in-Aid for Fundamental Scientific Research Fund of the Ministry of Education in 1971.

** Department of Fisheries, Faculty of Agriculture, Miyazaki University, Miyazaki, Japan (山根伸一: 宫崎大学呟学部水産增殖学教宝) 
on pellets in an aquarium with constant water temperature of $25^{\circ} \mathrm{C}$. The latter were bred in a concrete tank out of door. The water temperature of the tank was $19.0^{\circ} \mathrm{C}$ when fishes were taken out. They were killed with a scalpel stabbed in the metencephalon for examination.

Preparation of tissues In Mozambique mouthbrooder, tissues of the pharynx, the esophagus, a fundic part of the stomach, a proximal part of the intestine and the liver were cut out with a clean razor as rapidly as possible after killed. In bluegill, tissues of the same parts as in Mozambique mouthbrooder and the pyloric caeca in addition were treated likewise. The tissues were washed with cooled distilled water. Subsequently, each part of the tracts was split by a longitudinal slit. The lining surface of each part of the tracts and the surface of the liver or hepatopancreas were washed with physiological saline cooled at $0-2^{\circ} \mathrm{C}$. After blotted quickly on filter paper, the tissues were frozen in $n$-hexan cooled by dry-ice aceton for 3-5 minutes. The tissues were mounted in a microtome cryostat (Lipshaw cryotome model 1600) and fresh frozen serial sections were cut at $8 \mu$.

Preparation of starch film The method for the preparation of the starch substrate film followed that described in my previous paper ${ }^{13)}$.

Exposure of the film to tissue sections The tissue sections were placed in contact with the film, and immediately incubated in a moist chamber consisting of a petri dish containing wet filter paper at room temperature of $20-23^{\circ} \mathrm{C}$. In both species, the sections of the liver or hepatopancreas were incubated for 5, 10, 15 and 20 minutes, and those of the pharynx, the esophagus, the stomach, the pyloric caeca and the intestine were done for $10,15,20,30$ and 60 minutes. The process after incubation was the same as described in my previous paper ${ }^{13}$.

Localization of amylase activity can be identified as unstained indigested regions in the starch film. The tissue sections were left in contact with the film. This method helps to detect the localization of enzymatic activity. Some of the sections, however, peeled off while washing or rinsing in cooled distilled water.

To make further sure of the localization of the activity, alternate frozen sections of each part examined were stained with hematoxylin and eosin (H \& E).

Preparation of paraffin sections To observe a condition of pancreatic ramifications, paraffin sections of the pyloric caeca of the bluegill, and proximal parts of the intestine and the liver or hepatopancreas of both species were made at $5 \mu$ and stained with $\mathrm{H} \&$ E.

\section{Results}

Mozambique mouthbreeder. Pharynx This part showed amylase-negative.

Esophagus This part also showed amylase-negative. 
Stomach The mucosa, the submucosa, gastric glands and most regions of the muscularis showed amylase-negative. Amylase-positive reaction was found at the outerside of the muscularis, the serosa and the outside of the wall. That is, the starch film was digested in regions in contact with those parts and the stainability with iodine disappeared (Fig. 1a). Such relatively high activity in the muscularis and the serosa is unusual. It may be due to the amylase adhering to the wall of the stoamch when dissected from the mesenteric pancreatic tissues.

Intestine The mucosa and most parts of the submucosa showed amylase-negative. The starch film was digested in regions in contact with some parts of the submucosa being near the muscularis and the muscularis; and in regions corresponding to the lumen between mucosal folds and to the outer space of the tract (Fig. 2a and 3a). Such digestion of the film in contact with the former parts may be due to spread of the enzymatic activity of amylase existing primarily outside the tract. Ramifications of the pancreatic tissue were found to adhere to the wall of the tract in adjacent frozen sections stained with H \& E (Fig. 2b) and sections examined by the paraffin method (Fig. 12). The digestion of the regions of the film corresponding to the lumen may be due to amylase adhering to the luminal surfaces of epithelial cells.

Hepatopancreas The liver of Mozambique mouthbrooder was observed to be formed into a typical hepatopancreas. The starch film exposed to the tissue sections of this organ was digested in regions in contact with the pancreatic exocrine tissues and a big duct, the so-called choledochal duct (Fig. 4a). But, the film in contact with the tissues of the liver surrounding the pancreatic tissues was indigested. Since the digestion of the regions in contact with the pancreatic tissues occurred in whole area of those tissues of the sections, localization in the cytoplasm of the pancreatic exocrine cells could not be estimated. The digetion of the region in contact with the so-called choledochal duct is thought to be due to the pancreatic juice or the bile. The problem of whether or not this is ascribed to the bile will be discussed later. Two ducts, at least, were found in a common connective tissue and muscular sheath of the so-called choledochal duct (Fig. 4b).

Bluegill. Pharynx This part showed amylase-negative.

Esophagus. The starch film was weakly digested partially in regions corresponding to the lumen of the tract (Fig. 5a). This digestion may be due to amylase adhering to the luminal surfaces of the mucosa or that adsorbed in mucous substances adhering to the surface. The mucosa, the submucosa and the muscularis showed amylase-negative.

Stomach The starch film was digested in regions corresponding to the lumen. Especially, the region of the film near the remnants of stomach contents which attached to the lining surface of the mucosa, with mucous sbustances maybe, were strongly digested within 15 minutes incubation (Fig. 6a). The mucosa, the submucosa, the muscularis and gastric glands showed amylase-negative. Though there was a small spot unstained with 
LuGol's iodine in the region of the submucosa (Fig. 6a), this may be an artefact due to some reason.

Pyloric caeca The starch film was digested in regions corresponding to the luminal surfaces, the lumen between mucosal folds and the outside space of the tract; and in regions in contact with the outer layer of the muscularis (Fig. 7a). The mucosa and the submucosa showed amylase-negative. Ramifications of the pancreatic tissue adhered to the wall of the tract (Fig. 7b), and in some cases those penetrated into the longitudinal muscularis (Fig. 13). The digestion of the film in the regions in contact with the outer layer of the muscularis may be due to the spread of amylolytic activity of amylase contained in such pancreatic ramifications.

Intestine The film was digested partially in regions corresponding to the lumen between mucosal folds (Fig. 8a); and digested in regions in contact with the outer layer of the muscularis and corresponding to the outside of the tract (Fig. 8a). Ramifications of the pancreatic tissue adhered to the wall of the tract (Fig. 8b). In some cases the ramifications were embedded between the muscularis and the serosa (Fig. 14a), and invaded the longitudinal muscularis (Fig. 14b). The digestion of the film in the regions in contact with the outer layer of the muscularis may be due to the spread of the enzymatic activity of amylase contained in those pancreatic ramifications.

Liver Some regions of the film were digested (Fig. 9). Although the sections peeled off from the film while washing after incubation, the digested regions are thought to be coincided with the locality of the pancreatic tissues from comparison with neighbouring sections stained with $\mathrm{H} \& \mathrm{E}$. Some pancreatic ramifications were found to be slightly embedded to the liver only at the region which the hepatic portal vein entered to as seen in many teleosts possessing no hepatopancreas (Fig. 10).

Furthermore, the film was digested in regions in contact with the mesentery (Fig. 11).

\section{Discussion}

Some investigators ${ }^{3-8,9,11,18\}}$ considered that mucosal membranes of the stomach, the pyloric caeca and the intestine might be associated with the secretion of amylase, not only the pancreas. Especially, CHESLEY ${ }^{3)}$ stated that the pyloric caeca were more important in secretion of digestive enzymes in fishes possessing the diffuse pancreas. The amylolytic activity of fishes studied, which possess the diffuse pancreas, however, was not found in the mucosa and the submucosa of the digestive tract, even in the pyloric caeca, but demonstrated at the luminal surface and the lumen of the tract. Because amylase is recognized to be active in cytoplasm ${ }^{14,15)}$, this finding seems to testify that mucosal epithelial cells of the digestive tract are not concerned with the secretion or production of amylase. The high activity of amylase also detected in the diffuse pancreatic exocrine tissues attach- 
ing to or penetrating into the wall of the digestive tract and into the liver tissue. This evidence appears to indicate the pancreatic exocrine cells are concerned with the production of amylase, though the localization in the cytoplasm of those cells could not be estimated because of spread of the enzymatic activity. The amylolytic activity found at the outside or the outer- and outside of the wall of the tract may be due to amylase contained in the pancreatic ramifications or both amylase contained in those tissues and that adhering to the wall when dissection. The activity was also detected in the sections of the connective tissue and muscular sheath of the so-called choledochal duct of Mozambique mouthbrooder. From this one may assume that the bile has contained amylase. However, since the liver tissue examined showed no amylolytic activity, the bile which was secreted from the hepatic cells may have contained no digestive amylase. As for the digestive amylase in the bile, CHESLEY ${ }^{3)}$, BAYLISS ${ }^{4}$ and BABKIN and BowIE ${ }^{16)}$ detected its activity in some fishes. They, however, ground up the gall-bladder in the bile and extracted the whole. BABKIN and BowIE stated themselves the possibility that enzymes of the pancreas which tissues enveloped the gall-bladder might have become mixed with the bile. The ramifications of diffuse pancreas seem to surround usually the bile duct and the gall-bladder ${ }^{17}$. According to HALE ${ }^{17}$, the choledochal ducts of Poecilia reticulata and Gasterosteus aculeatus do not join with the pancreatic duct though both kinds of duct run parallel within a common connective tissue and muscular sheath. KErL (quoted by HALE ${ }^{17}$ ) described the same evidence in the carp, tench and stone-loach. I also observed the same in the connective tissue and muscular sheath of the so-called choledochal duct of bluegill by serial sections of digestive system (unpublished data). Such may be then also the case in Mozambique mouthbrooder. Actually two ducts were observed. It is easily deduced that the pancreatic duct may have been located in the connective tissue and muscular sheath of the so-called choledochal duct. Consequently the amylolytic activity found in the sections of the so-called choledochal duct and its sheath may be due to the pancreatic juice. Therefore, it seems to be concluded that the locality of digestive amylase production is confined to the pancreatic exocrine cells alone even in fishes possessing the pyloric caeca. The present results are accordant with that in $\operatorname{carp}^{13)}$. Amylase may be secreted from the pancreas alone in teleosts independently of variety of digestive tract.

SULLIVAN (quoted by BARRINGTON ${ }^{18}$ ) found amylolytic activity in the pancreatic extracts of elasmobranchs. BARRINGTON ${ }^{18}$ described that no presence of amylase in the intestinal mucosa of elasmobranchs seemed to be recorded. From those finding and statement and the present results, amylase production confined to the pancreas alone may be common among Chondrichtyes and Teleostei.

According to TONER et al. ${ }^{19}$, a fuzzy coat exists at the luminal surface of the intestine; is apparently attached to the cell membrane; and is consisted mainly of acid mucopolysaccharides. OzAKi ${ }^{20)}$ also observed such fuzzy materials at the luminal surfaces of the 
intestinal mucosal cells of the gold fish. Microvilli are well known to be formed at the luminal surface of the mucosal epithelial cells, especially of absorptive cells. The survival of relatively high activity of amylase at the luminal surfaces or the lumen of the pyloric caeca and the intestine after washing may be related to such architecture and materials. It should be taken into account in biochemical works that digestive enzymes adbering to the luminal surfaces or that contained in the pancreatic ramifications adhering to the tract or both are possibly homogenized with tissues of the digestive tract and extracted together.

Amylase secreted into the intestinal lumen through the pancreatic duct seems to be easily regurgitated to the lumen of the stomach and even to that of the esophagus through the stomach.

\section{Acknowledgements}

I wish to express the gratitude to Professor Masao Kimura of Miyazaki University for his encouragement throughout the study and to Drs. Eizo Mizunuma and Masato AKAZAKı for their offer of the bluegills examined in the present study.

\section{References}

1) H. J. Vonk: Biol. Rev., 12, 245-284 (1937).

2) A. Bondi and A. SPANDORF: Brit. J. Nutr., 18, 240-246 (1954).

3) L. C. Chesley: Biol. Bull, 66, 133-144 (1934).

4) L. E. BAYLiss: J. Mar, Biol. Ass. U. K., 20, 73-91 (1935).

5) J. IsHidA: Annot. Zool. Jap., 15, 182-189 (1935).

6) A. H. Al-Hussaini: Quart. J. Microscop. Sci., 90, 323-354 (1949).

7) D.S. SARBahi: Biol. Bull., 100, 244-257 (1951).

8) K. TAKesue: J. Shimonoseki Coll. Fish., 3, 289-294 (1954).

9) G. R. Fish: Hydrobiologia, 15, 161-178 (1960).

10) A. JANCARIK: Z. Fisch., 12, 601-684 (1964).

11) G. Nagase: Z. verg. Physiol., 49, 270-284 (1964).

12) S. KaWAI and S. IKEDA: This Bull, 37, 333-337 (1971).

13) S. YAMANE: This Bull, 39, 497-504 (1973).

14) H. W. Davenport: Physiology of the Digestive Tract, 2nd ed., 230 pp., Year Book Medical Pub. Inc., Chicago (1966).

15) R. J. Smith, J. Frommer and R. Schiff: J. Histochem. Cytochem., 19, 310-319 (1971).

16) B. P. BABKIN and D. J. Bowie: Biol. Bull., 54, 254-277 (1928).

17) A. P. Hale: J. Zool, 146, 132-149 (1965).

18) E. J. W. Barrington: in "The Physiology of Fishes" (M. E. Brown, ed.), vol. 1, 109-161, Academic Press, New York (1957).

19) P. G. Toner, K. E. CARr and G. M. Wyburn: The Digestive System-An Ultrastructural Atlas and Review, 303 pp., Butterworth \& Co. (Publishers) Ltd., London (1971).

20) N. OZAKI: Arch. Histol. Jap., 26, 23-38 (1965). 

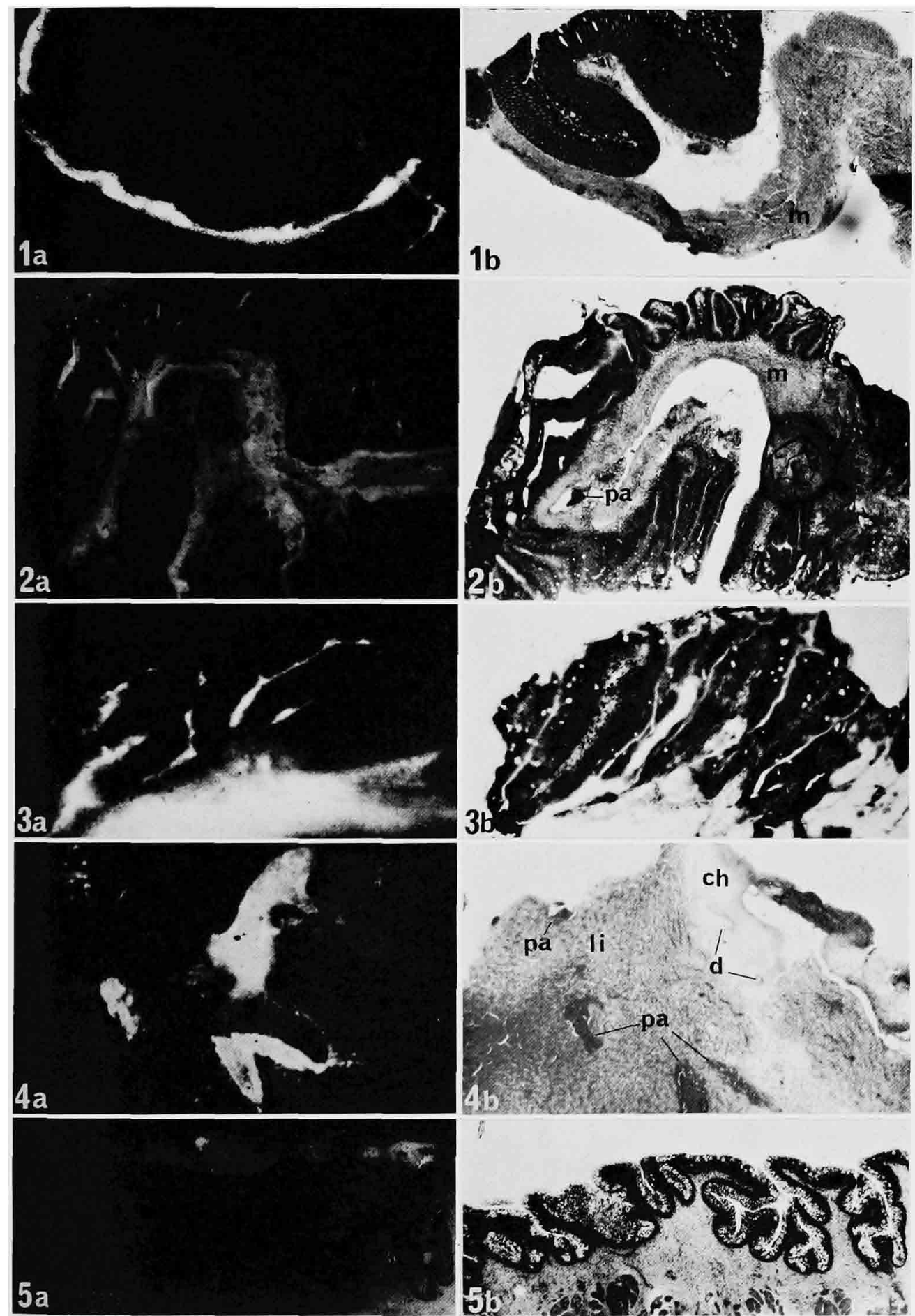

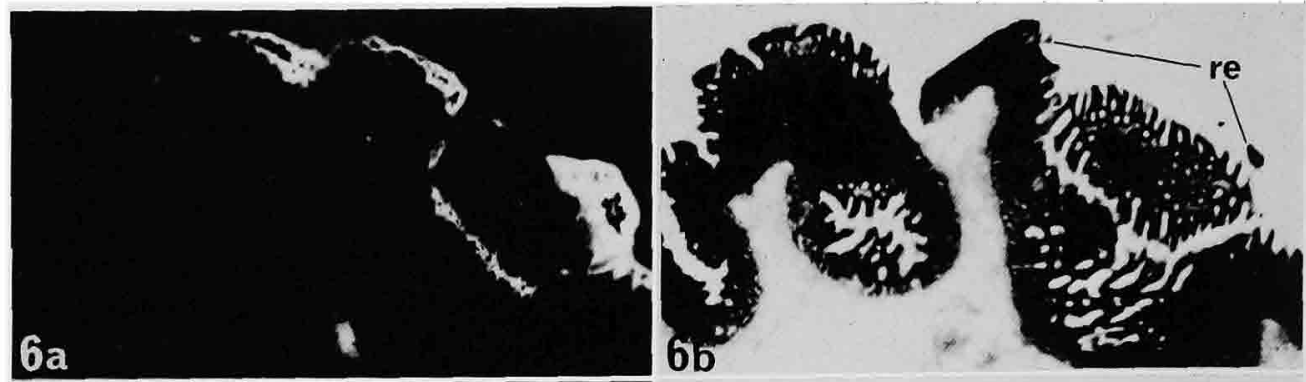

\section{$7 a$}
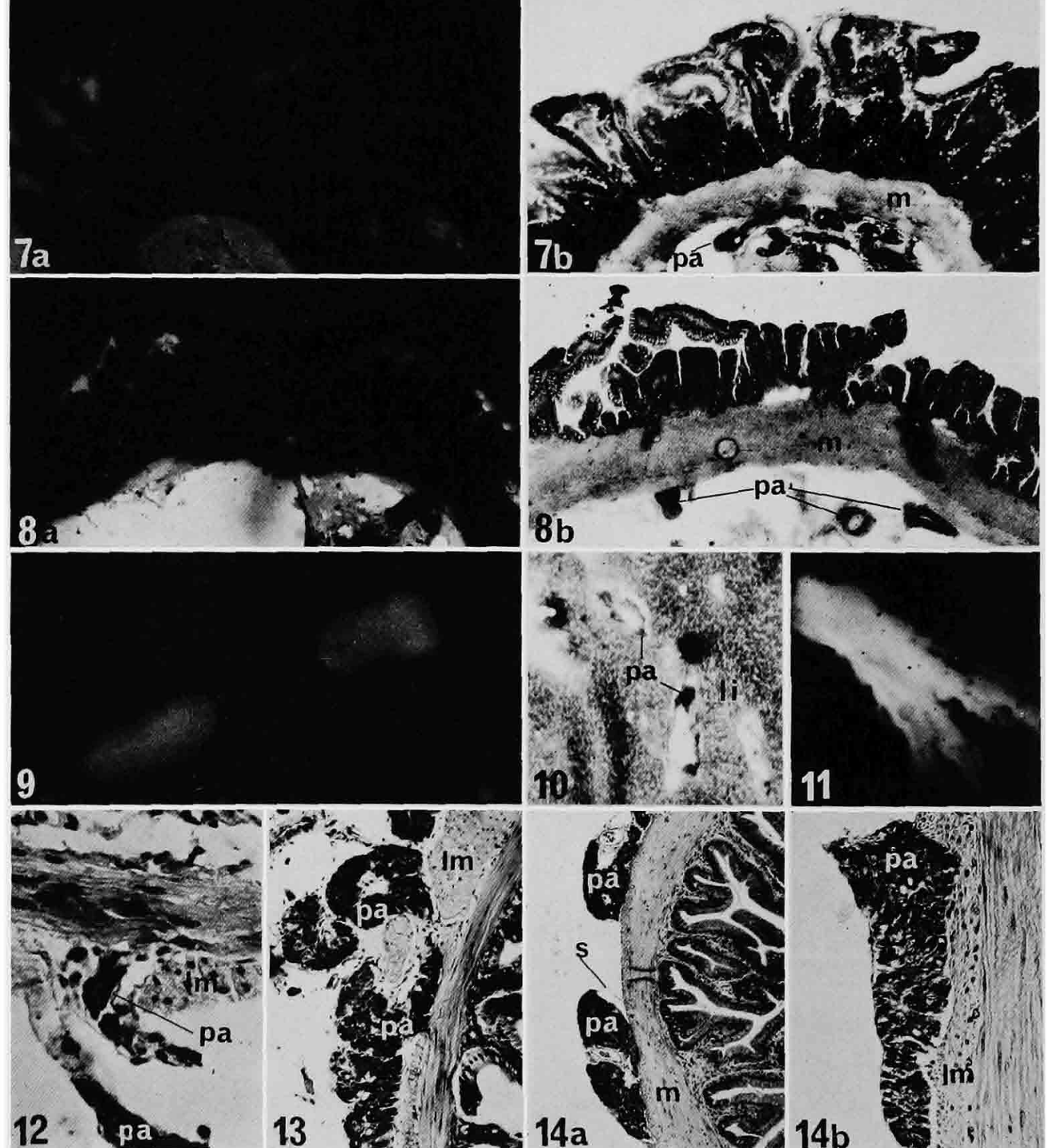

10
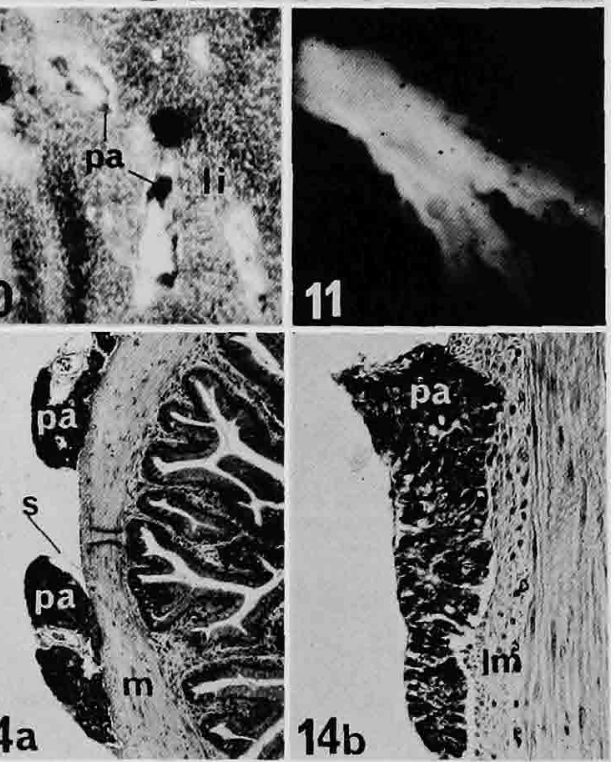


\section{Explanation of Plates}

Fig. 1. Stomach of Mozambique mouthbrooder: $a-a$ fresh frozen section examined by the starch substrate film method, incubation for $30 \mathrm{~min}$; $b-$ that stained with hematoxylin and eosin $(H \& E) . \quad \times 29$.

Fig. 2. Intestine of Mozambique mouthbrooder: a-a fresh frozen section examined by the starch substrate film method, incubation for $30 \mathrm{~min}$; b-that stained with H \& E. $\times 29$.

Fig. 3. Intestine of Mozambique mouthbrooder: a-a fresh frozen section examined by the starch substrate film method, incubation for $60 \mathrm{~min}$; b-that stained with $\mathrm{H} \& \mathrm{E} . \quad \times 29$.

Fig. 4. Hepatopancreas of Mozambique mouthbrooder: a-a fresh frozen section examined by the starch substrate film method, incubation for $5 \mathrm{~min}$; $b$ - that stained with $H \& E$. $\times 45$.

Fig. 5. Esophagus of bluegill: a-a fresh frozen section examined by the starch substrate film method, incubation for $60 \mathrm{~min}$; b-that stained with H \& E. $\times 29$.

Fig. 6. Stomach of bluegill: $a-a$ fresh frozen section examined by the starch substrate film method, incubation for $15 \mathrm{~min}$; $\mathbf{b}$ - that stained with $\mathrm{H} \& \mathrm{E} . \quad \times 29$.

Fig. 7. Pyloric caeca of bluegill: $\mathbf{a}-\mathbf{a}$ fresh frozen section examined by the starch substrate film method, incubation for $10 \mathrm{~min}$; $\mathbf{b}-$ that stained with $\mathrm{H} \& \mathrm{E} . \quad \times 29$.

Fig. 8. Intestine of bluegill: $\mathbf{a}-\mathrm{a}$ fresh frozen section examined by the starch substrate film method, incubation for $10 \mathrm{~min}$; $\mathbf{b}$-that stained with $\mathrm{H} \& \mathrm{E} . \quad \times 29$.

Fig. 9. Starch substrate film exposed a fresh frozen section of the liver of bluegill, incubation for $10 \mathrm{~min} . \quad \times 29$.

Fig. 10. A fresh frozen section of the liver of bluegill stained with H \& E. $\times 29$.

Fig. 11. Starch substrate film exposed a fresh frozen section of the mesentery, incubation for $10 \mathrm{~min} . \times 29$.

Fig. 12. A section of the intestine of Mozambique mouthbrooder examined by paraffin method, stained with $\mathrm{H} \& \mathrm{E} . \quad \times 376$.

Fig. 13. A section of the pyloric caeca of bluegill examined by paraffin method, stained with H \& E. $\times 96$.

Fig. 14. Sections of the intestine of bluegill examined by paraffin method, stained with $H$ \& E: $a-\times 53 ; b-\times 217$.

Abbreviations. ch: the connective tissue and muscular sheath of the so-called choledochal duct, d: duct, li: liver, Im: longitudinal muscularis, $\mathbf{m}$ : muscularis, pa: pancreas, re: the remnant of contents of the digestive tract, s: serosa. 